\title{
Fibra Bruta para Alevinos de Tilápia do Nilo (Oreochromis niloticus, L)
}

\author{
Fábio Meurer ${ }^{1}$, Carmino Hayashi², Wilson Rogério Boscolo 3
}

\begin{abstract}
RESUMO - Este experimento objetivou avaliar diferentes níveis de fibra bruta no desempenho e no tempo de retenção do bolo alimentar em alevinos de tilápia do Nilo (Oreochromis niloticus, L). Foram utilizados 125 alevinos (1,39 $\pm 0,03 \mathrm{~g})$ distribuídos em 25 aquários de $54 \mathrm{~L}$, em um delineamento inteiramente casualizado, com cinco tratamentos e cinco repetições. Foram formuladas cinco rações isoenergéticas (3000 kcal/kg de energia digestível) e isoprotéicas (30\% de proteína bruta), diferindo quanto aos níveis de fibra bruta (3,65; 4,$75 ; 6,00 ; 7,25$ e $8,50 \%$ ). O período experimental foi de 64 dias a uma temperatura média de $26,5^{0} \mathrm{C} \pm 0,8$ de manhã e $27,5^{0} \mathrm{C} \pm 0,7$ à tarde. Não foram observadas diferenças quanto ao desempenho dos alevinos, entretanto houve decréscimo linear para o tempo de retenção do bolo alimentar com o aumento da fibra.
\end{abstract}

Palavras-chave: celulose, fibra, nutrição, Oreochromis, peixe, tilápia

\section{Crude Fiber for Nile tilapia (Oreochromis niloticus, L) Fingerlings}

\begin{abstract}
This work aimed to evaluate different crude fiber levels on reverted Nile tilapia (Oreochromis niloticus, L) fingerlings performance and time of retention of food. One hundred and twenty-five fingerlings of Thai strain, $1.39 \pm 0.03 \mathrm{~g}$ of initial weight were allotted to twenty-five $54 \mathrm{~L}$ aquarium, at five treatments and five replications on completely randomized design. Five isoenergy (3000 $\mathrm{kcal} / \mathrm{kg}$ of digestible energy) and isoprotein (30\% of crude protein) diets were formulated with five different crude fiber levels (3.65, $4.75,6.00,7.25$ and $8.50 \%$ ), for ranging cellulose and inert material addition. The experimental period was 64 days with $26.5^{0} \mathrm{C} \pm 0.8$ in the morning and $27.5^{\circ} \mathrm{C} \pm 0.7$ in the afternoon temperatures. No difference was observed to fingerlings performance (food conversion, final weight, weight gain), but a linear decrease to time of retention of food with crude fiber addition.
\end{abstract}

Key Words: cellulose, fiber, fish, nutrition, Oreochromis, tilapia

\section{Introdução}

A tilapicultura vem se mostrando uma ótima alternativa para a piscicultura de água doce e estuarina. A expansão do cultivo da tilápia do Nilo (Oreochromis niloticus) deve-se ao ótimo desempenho, à alta rusticidade, facilidade de obtenção de alevinos, adaptabilidade aos mais diversos sistemas de criação e grande aceitação no mercado de lazer (pesque-pague) e alimentício (frigoríficos), pelas qualidades nutritivas e organolépticas do seu filé (Meurer, 2002).

A fração fibra bruta dos alimentos é composta principalmente de celulose, lignina e pequena quantidade de hemicelulose e substâncias pécticas (Hilton, et al., 1983; Larbier \& Leclerq, 1992). A composição desta fração pode variar bastante de acordo com a espécie e idade da planta (Andriguetto et al., 1981; Mayanard et al., 1984).

A celulose é o material orgânico natural mais abundante do planeta (Lehninger et al., 1995; Bullock et al., 2000), sendo o principal constituinte da parede celular de plantas (Lassiter \& Eduards, 1982; Maynard et al., 1984). É um polissacarídeo linear que possui como unidade monomérica a glicose ligada por uma ligação glicosídica $\beta(1 \rightarrow 4)$, devido a estas ligações, as cadeias de glicose assumem uma conformação alongada e agregam-se lado a lado formando fibrilas insolúveis, estas fibrilas por sua vez dispõe-se em camadas entrecruzadas, o diâmetro destas microfibrilas variam de 3 a $10 \mathrm{~nm}$ (Harris \& Ferguson, 1999) e podem ser impregnadas com uma matriz cimentante formada por polissacarídeos de diferentes tipos e uma substância polimérica denominada lignina.

A degradação da celulose depende de uma enzima denominada celulase, que hidrolisa as ligações glicosídicas $\beta(1 \rightarrow 4)$, expondo as unidades de glicose para a absorção, entretanto o sistema digestivo dos vertebrados não secreta esta enzima (Lehninger, 1991), sendo esta dependente exclusivamente de fontes exógenas, tais como os microorganismos pre-

\footnotetext{
${ }^{1}$ Zootecnista, M.S., Professor Assistente do curso de Medicina Veterinária da Pontifícia Universidade Católica do Paraná (PUCPR), Campus de Toledo, Av. da União, 500, Jardim Coopagro, CEP: 85902-532, Toledo-PR. E.mail: fabiomeurer@pop.com.br; fmeurer@rla01.pucpr.br

2 Prof. Titular do Depto de Biologia - UEM. E.mail: chayashi@uem.br

3 Zootecnista, Msc., Prof. de Engenharia de Pesca/UNIOESTE, pós-graduando/PPZ - UEM. E.mail wrboscolo@bol.com.br
} 
sentes no trato gastrintestinal, principalmente no intestino grosso e ceco.

Em monogástricos, a fibra é responsável por uma pequena parcela da energia da dieta, o que se faz através da digestão desta por microorganismos, no intestino grosso e ceco (Lassiter \& Eduards, 1982). A importância desta no total do requerimento energético varia bastante conforme a espécie, a idade e o estado fisiológico dos animais, e em alguns cultivos sua presença fica condicionada a percentagem que esta se apresenta no alimento.

De acordo com Pereira-Filho (1992), os resultados de pesquisas sobre o efeito de diferentes níveis de fibra bruta na dieta de peixes são contraditórios. Wilson (1995) afirma que a fibra bruta é um componente dos alimentos constituintes da ração, sendo indigestível para a maioria das espécies de peixes, não devendo ser adicionada ao alimento. Segundo esse mesmo autor, deve ser mantida o mais baixo quanto possível pelo seu efeito deletério na qualidade da água dos sistemas de cultivo.

A influência da fibra no desempenho de peixes é ainda pouco estudada, podendo estar relacionada com a sua composição percentual em celulose, hemicelulose, lignina e sílica, entre outros. Hayashi et al. (2000), estudando a influência de diferentes fontes de fibra no desempenho de alevinos revertidos de tilápia do Nilo, verificaram diferenças entre os tratamentos, encontrando melhores resultados de ganho de peso para os alevinos alimentados com rações contendo sabugo de milho e bagaço de cana hidrolisado, em relação a rações contendo bagaço de cana e a casca de arroz como fontes de fibra. Bach Knudsen et al. (1995) observaram redução linear da digestibilidade verdadeira da proteína e energia, à medida que se aumenta o nível de fibra dietária na ração de ratos.

De acordo com Pezzato (1997, 1999), a celulose é considerada como uma fonte de energia não disponível, e que em alguns peixes herbívoros há a produção de celulase pelas suas bactérias intestinais. Um dos pontos onde a fibra tem importância é a influência que esta apresenta sobre a motilidade do trato digestivo e, conseqüentemente, sobre a velocidade de trânsito do alimento pelo mesmo (Lassiter \& Eduards, 1982; Argenzio, 1988; Shiau, 1997).

De acordo com Ensminger \& Olentine (1980), pela simplicidade do trato gastrintestinal dos peixes, a digestibilidade da fibra é muito baixa, menos de $10 \%$, e a mesma serve como fonte de volume e como aglutinante, recomendando-se não mais de $10 \%$ na dieta, preferivelmente entre 5 e $6 \%$. Entretanto, Zonneveld \& Zon (1985) destacam que carpas capim adultas (Ctenopharyngodon idella) tem uma flora microbiana intestinal que permite realizar a síntese de aminoácidos e peptídeos a partir da fibra dietária.

O objetivo do presente trabalho foi, avaliar o efeito da inclusão de níveis crescentes de fibra bruta na ração, sobre o desempenho e tempo de retenção do bolo alimentar em alevinos de tilápia do Nilo da linhagem tailandesa, revertidos sexualmente.

\section{Material e Métodos}

O experimento foi realizado no Laboratório de Aquiicultura do Departamento de Biologia da Universidade Estadual de Maringá, de 24 de fevereiro a 30 de abril de 2000. Foram utilizados 125 alevinos de tilápia do Nilo, da linhagem tailandesa e revertidos sexualmente, com peso de 1,39 $\pm 0,03 \mathrm{~g}$, distribuídos em 25 aquários de $54 \mathrm{~L}$ em um delineamento inteiramente casualizado com cinco tratamentos e cinco repetições, onde cada aquário com cinco alevinos foi considerado como uma unidade experimental.

Os aquários possuíam aeração constante, através de pedras microporosas ligadas, por meio de mangueiras num soprador de $1 / 4 \mathrm{cv}$, e a temperatura mantida através de aquecedores com termostatos. Os aquários foram sifonados duas vezes ao dia, de manhã e à tarde, cada sifonagem retirava $20 \%$ do volume de água do aquário. A temperatura da água dos aquários foi aferida no início da manhã e no final da tarde, antes da sifonagem; o oxigênio dissolvido, $\mathrm{pH}$ e condutividade foram aferidos uma vez por semana, durante o período da manhã, também antes da sifonagem.

As rações (Tabela 1) foram formuladas de acordo com as exigências nutricionais da espécie (NRC, 1993). Para a elaboração das rações os ingredientes foram triturados em um moinho de facas, com peneira de $0,5 \mathrm{~mm}$, com exceção da celulose que foi moída em peneira de 1,0 mm. Após a moagem, os ingredientes foram misturados, umedecidos com água a $50^{\circ} \mathrm{C}$ e peletizados manualmente. Os peletes foram moídos e separados em classes de tamanhos, por meio de passagem por peneiras de malhas de vários tamanhos, para que se fizesse a adequação dos mesmos ao tamanho da boca dos alevinos. Foi fornecido $10 \%$ do peso vivo dos alevinos de ração, três vezes ao dia, quantidade que foi aferida a cada dez 
dos aquários, não apresentaram diferenças estatísticas entre os tratamentos $(\mathrm{P}>0,05)$ e mantiveram-se dentro dos padrões descritos por Popma \& Phelps (1998) para o bom desenvolvimento da espécie.

Os valores médios de peso inicial, peso final, ganho de peso em gramas, ganho de peso em percentagem, retenção do bolo alimentar, conversão alimentar e sobrevivência dos alevinos de tilápia do Nilo estão apresentados na tabela 2.

A retenção do bolo alimentar apresentou diminuição linear em relação ao aumento dos níveis de fibra bruta nas rações. Hilton et al. (1983), também obtiveram decréscimo no retenção do bolo alimentar com o aumento do conteúdo de fibra bruta na ração para juvenis de truta arco-íris (Oncorhynchus mykiss). O efeito da fibra dietária sobre o retenção do bolo alimentar é relatada por vários autores (Lassiter \& Eduards, 1982; Shiau ,1997). A retenção do bolo alimentar pelo trato digestivo do animal, é responsável pelo tempo que alimento fica exposto aos processos digestivos e absortivos do organismo influenciando a sua eficiência (NRC, 1993). Geralmente, observa-se que a celulose diminui o tempo de esvaziamento do trato gastrintestinal ao contrário do que ocorre com polissacarídeos não-amilaceos solúveis (Wenk, 2001).

Uma dieta que promova baixa retenção do bolo alimentar pode resultar em menor aproveitamento do alimento, uma vez que o mesmo permanece um tempo insuficiente no trato digestivo para sofrer os processos de digestão e absorção. Entretanto, tempo excessivo de permanência do alimento no trato digestivo levaria a menor desempenho do animal, pelo fato de a parte indigestível ou digerida e não absorvida de um alimento ocupar o espaço que poderia estar sendo ocupado por um novo alimento (Meurer et al., 2002). Hilton et al. (1983) demonstraram redução linear da digestibilidade da matéria seca, à medida que se elevaram os níveis de celulose na ração.

A fibra incrementa o volume de uma ração (Ensminger \& Olentine, 1980), influenciando a retenção do bolo alimentar, pois de acordo com Argenzio (1988), a velocidade de esvaziamento do trato digestivo depende do volume e da distensão gástrica, os quais constituem o estímulo primário para aumentar a motilidade gástrica. No entanto se a fonte de fibra utilizada contiver muita hemicelulose e/ou pectina pode ocorrer uma situação contrária, pois estes componentes da fração fibra bruta aumentam a viscosidade do bolo alimentar, que por sua vez leva a uma resistência às contrações propulsivas do trato digestivo (Ferreira, 1994).

A maior retenção do bolo alimentar pode permitir maior multiplicação dos microorganismos do intestino grosso e sua migração para o intestino delgado (Bedford, 1995). O aumento da atividade microbiana, no intestino delgado acarreta incremento da competição do alimento disponível com o hospedeiro, a produção de metabólitos tóxicos como a amônia, aminas, ácidos biliares secundários e enterotoxinas bacterianas. (Bedford, 1995; Yin et al., 2000).

Os valores médios de peso final, ganho de peso e conversão alimentar não apresentaram diferenças estatísticas $(P>0,05)$ em relação aos níveis crescentes de fibra bruta na dieta, concordando com Anderson et al. (1984), encontraram valores semelhantes para tilápia do Nilo. Entretanto, Al-ogaily (1996) observou

Tabela 2 - Parâmetros avaliados nos alevinos de tilápia do Nilo submetidos a níveis crescentes de fibra na ração Table 2 - Evaluated parameters at Nile tilapia fingerlings fed diets with increasing fiber levels

\begin{tabular}{|c|c|c|c|c|c|c|}
\hline \multirow[b]{2}{*}{$\begin{array}{l}\text { Média das variáveis } \\
\text { Mean of variables }\end{array}$} & \multicolumn{5}{|c|}{$\begin{array}{c}\text { Níveis de fibra na dieta }(\%) \\
\text { Level of fiber in diet }\end{array}$} & \multirow[b]{2}{*}{$\mathrm{CV}(\%)$} \\
\hline & 3,65 & 4,75 & 6,00 & 7,25 & 8,50 & \\
\hline Peso inicial (g) (Initial weight) & 1,39 & 1,38 & 1,39 & 1,39 & 1,41 & 2,30 \\
\hline Peso final (g) (Final weight) & 7,27 & 8,25 & 7,05 & 7,36 & 6,65 & 20,05 \\
\hline Ganho de peso (g) (Weight gain) & 5,88 & 6,87 & 5,66 & 5,97 & 5,25 & 24,53 \\
\hline Ganho de peso (\%) (Weight gain) & 421,22 & 497,87 & 408,59 & 428,36 & 372,07 & 23,66 \\
\hline $\mathrm{TR}^{1}$ (horas) $^{1} T^{1}$ (hours) $^{1}$ & 2,60 & 2,50 & 2,50 & 2,05 & 1,95 & 9,87 \\
\hline Conversão alimentar (Feed:gain ratio) & 0,96 & 0,95 & 0,97 & 0,98 & 0,99 & 8,14 \\
\hline Sobrevivência (\%) (Survival rate) & 88,00 & 80,00 & 84,00 & 80,00 & 84,00 & 17,66 \\
\hline
\end{tabular}

1 Tempo de retenção do bolo alimentar (food retention time).

2 Efeito linear (linear effect): $\hat{Y}=3,18869-0,00144061 x, r^{2}=0,53 .^{2}: y=3,18869-0,00144061 x, r^{2}=0,53$. 
que o nível de $9 \%$ de celulose na ração de juvenis de tilápia do Nilo proporcionou maior desempenho; Diondick \& Stom (1990), também encontraram maior índice de crescimento de alevinos de tilápia moçambica (O. mossambicus) quando alimentados com rações contendo 2,5 e 5,0\% de fibra bruta em relação às que continham 0,0 e $10,0 \%$. Shiau et al. (1998)constataram diminuição do desempenho e piora na conversão alimentar de tilápias do Nilo alimentadas com níveis crescentes de carboximetilcelulose na ração.

O desempenho semelhante apresentado pelos peixes dos diferentes tratamentos pode ser explicado pelo uso de rações isonutritivas, onde variou apenas a quantidade de celulose e material inerte (areia de barranco). Segundo Hilton et al. (1983), a celulose é pouco ativa no tocante a indisponibilização de minerais para a absorção intestinal. Associado a isto, a variação na retenção do bolo alimentar, entre os tratamentos, não foi suficiente para que houvesse diminuição do aporte de nutrientes para a absorção que pudesse refletir significativamente no desempenho dos animais.

\section{Conclusões}

O aumento dos níveis de fibra bruta de 3,65 a $8,50 \%$, pela inclusão de celulose, em rações para alevinos revertidos de tilápia do Nilo não influenciou o desempenho e a sobrevivência dos mesmos, porém causou decréscimo linear da velocidade de trânsito do bolo alimentar.

\section{Literatura Citada}

AL-OGAILY, S.M. Effect of feeding different levels of cellulose on the growth performance and body composition of Oreochromis niloticus. Arab. Gulf. J. Scient. Res., v.14, n.3, p.731-745, 1996.

ANDERSON, J.; JACKSON, A.J.; MATTY, A.J. et al. Effects of dietary carbohydrate and fibre on tilapia (Oreochromis niloticus). Aquaculture, v.37, p.303-314, 1984.

ANDRIGUETTO, J.M.; PERLY, L.; MINARDI, I. et al. Nutrição animal. As bases e os fundamentos da nutrição animal os alimentos. 4.ed. São Paulo: Nobel, 1981. v.1, 395p.

ARGENZIO, R.A. Motilidade gastrintestinal. In: SWENSON, M.J. (Ed.) Dukes fisiologia dos animais domésticos. 10.ed. Rio de Janeiro: Guanabara Koogan, 1988. p.243-252.

BACH KNUDSEN, K.E.; STEENFELDT, S.; BORSTING, C.F. et al. The value of decorticated mill fractions of wheat. 1 . Chemical composition of raw and enzyme treated fractions and balance experiments with rats. Animal Feed Science and Technology, v.52, p.205-225, 1995.

BEDFORD, M.R. Mechanism of action and potential environmental benefits from the use of feed enzymes.Ani- mal Feed Science and Technology, v.53, p.145-155, 1995.

BULLOCK, G.; BLAZER, V.; TSUKUDA, S.; et al. Toxicity of acidified chitosan for cultured rainbow trout (Oncorhynchus mykiss). Aquaculture, v.185, p.273-280, 2000.

DIONDICK, O.B.; STOM, D.I. Effects of dietary \& alpha;cellulose levels on the juvenile tilapia, Oreochromis mossambicus (Peters). Aquaculture, v.91, n.3-4, p.311315, 1990.

ENSMINGER, M.E.; OLENTINE, C.G. Feeds \& nutrition. California: Ensminger Publishing Company, 1980. 1417p.

FERREIRA, W.M. Os componentes da parede celular vegetal na nutrição de não-ruminates. In: SIMPÓSIO INTERNACIONAL DE PRODUÇÃO DE NÃO-RUMINANTES, 1., 1994, Maringá. Anais... Maringá: Sociedade Brasileira de Zootecnia, 1994. p.85-113.

HARRIS, P.J.; FERGUSON, L.R. Dietary fibres may protect or enhance carcinogenesis. Genetic Toxicology and Environmental Mutagenesis, v.443, p.95-110, 1999.

HAYASHI, C.; BOSCOLO, W.R.; SOARES, C.M.; et al. Uso de diferentes graus de moagem dos ingredientes em dietas para tilápia do Nilo (Oreochromis niloticus L.) na fase de crescimento. Acta Scientiarum, v.21, n.3, p.733-737, 1999.

HAYASHI, C; MEURER, F; BOSCOLO, W.R; et al. Fontes de fibra no desempenho de alevinos de tilápia do Nilo. Acta Scientiarum, v.22, n.3, p.689-694, 2000.

HILTON, J.W.; ATKINSON, J.L.; SLINGER, S.J. Effect of increased dietary fiber on the growth of rainbow trout (Salmo gardneri). Canadian Journal of Fisheries Aquatic Science, v.40, p.81-85, 1983.

JAUNCEY, K.; ROSS, B.A guide to tilapia feeds and feeding. Institute of Aquaculture. Scotland: University of Stirling. 1982.

LARBIER, M.; LECLERCQ, B. Nutrition and Feeding of Poultry. Nottingham University Press, 1992. 305p.

LASSITER, J.M.; EDUARDS Jr, H.M. Animal nutrition. Reston Publishing Company. 1982.

LEHNINGER, A.L.Princípios de bioquímica. 7.ed. São Paulo: Sarvier, 1991. 725p.

LEHNINGER, A.L.; NELSON, D.L.; COX, M.M.Princípios de Bioquímica. 2.ed. São Paulo: Sarvier, 1995. 839p.

MAYNARD, L.A.; LOOSLI, J.K.; HINTZ, H.F.; et al.Nutrição Animal. 3.ed. São Paulo: Livraria Freitas Bastos S.A. 1984. $756 \mathrm{p}$.

MEURER, F. Digestibilidade aparente dos nutrientes e energia de alguns alimentos protéicos para juvenis de tilápia do Nilo (Oreochromis niloticus L.), e efeito do processamento da ração durante a reversão sexual. Maringá: Universidade Estadual de Maringá, 2002. Dissertação (Mestrado em Produção Animal) - Universidade Estadual de Maringá, 2002. 57p.

MEURER, F.; HAYASHI, C.; BOSCOLO, W.R. et al. Lipídeos na alimentação de alevinos revertidos de tilápia do Nilo (Oreochromis niloticus, L). Revista Brasileira de Zootecnia, v.31, n.2, p.566-573, 2002.

NATIONAL RESEARCH COUNCIL - NRC. Nutrient requirements of warm water, fishes and shellfishes: nutrient requirements of domestic animals. Washington, D.C.: 1993. 114p.

PEREIRA-FILHO, M. Importância da fibra na nutrição dos peixes. In: SIMPÓSIO BRASILEIRO DE AQUICULTURA, 7., 1992, Peruíbe. Anais... Peruíbe: ABRAq, 1992. p.1-10.

PEZZATO, L.E. Alimentos convencionais e não-convencionais disponíveis para indústria da nutrição de peixes no Brasil. In: 
SIMPÓSIO INTERNACIANAL SOBRE NUTRIÇÃO E CRUSTÁCEOS, 1, 1995, Campos de Jordão.Anais...Campos de Jordão: Colégio Brasileiro de Nutrição Animal, 1995. p.34-52.

PEZZATO, L.E. Alimentação de peixes: relação custo x benefício. In: REUNIÃO ANUAL DA SOCIEDADE BRASILEIRA DE ZOOTECNIA, 36., 1999, Porto Alegre. Anais... Porto Alegre: Sociedade Brasileira de Zootecnia, 1999. (CD ROM)

PEZZATO, L.E. O estabelecimento das exigências nutricionais das espécies de peixes cultivadas. In: SIMPÓSIO SOBRE MANEJO E NUTRIÇÃO DE PEIXES, 1., Piracicaba. Anais... Piracicaba: Sociedade Brasileira de Zootecnia, 1997. p.45-62.

POPMA, T.J., PHELPS, R.P. Status report to commercial tilápia producers on monosex fingerling productions techniques. In: SIMPÓSIO SUL AMERICANO DE AQUICULTURA, 1., 1998, Recife.Anais...Florianópolis: SIMBRAQ, 1998. p.127.

ROSTAGNO, H.S.; SILVA, D.J.; COSTA, P.M.A. Composição de alimentos e exigências e nutricionais de aves e suínos (Tabelas brasileiras). 1.ed. Viçosa: Departamento de Zootecnia. 1994. 49p.

SHIAU, S.Y. Utilization of carbohydrates in warmwater fish with particular reference to tilapia, Oreochromis niloticus $\mathrm{x}$ O. aureus. Aquaculture, v.151, n.1-4. p.79-96, 1997.

SHIAU, S.Y.; YU, H.L.; HWA, S. et al. The influence of carboxymethylcellulose on growth, digestion, gastric emptying time and body composition of tilapia. Aquaculture, v.70, p.345-354, 1998.
SINTAYEHU, A.; MATHIES, E.; MEYER-BURFDORFF, K.H. Apparent digestibilities and growth experiment with tilapia (Oreochromis niloticus) fed soybean meal, cottonseed meal and sunflower seed meal. Journal of Applied Ichthyology, v.12, n.2, p.125-130, 1996.

UNIVERSIDADE FEDERAL DE VIÇOSA - UFV.SAEG Sistema para análises estatísticas e genéticas. Versão 7.1. Viçosa, MG. 150p. (Manual do usuário).

WENK, C. The role of dietary fibre in the digestive physiology of the pig. Animal Feed Science and Technology, v.90, p.21-33, 2001.

WILSON, R.P. Lipid nutrition of finfish. Nutrition and utilization technology. In: LIM, C; SESSA, D.J. (Eds.) Nutrition and utilization technology in aquaculture. Champaign: AOAC Press, 1995. p.74-81.

YIN, Y.L., MCEVOY, J.D.G., SCHULZE, H. et al. Apparent digestibility (ileal an overall) of nutrients and endogenous nitrogen losses in growing pigs fed wheat (var. Soissons) or its by-products without or with xylanase supplementation. Livestock Production Science, v.62, p.119-132, 2000.

ZONNEVELD, N.; ZON, H.V. The biology and culture of grass carp (Ctenopharyngodon idella), with special reference to their utilization for weed control. In: MUIR, J.F.; ROBERTS, R.J. (Ed.) Recents advances in aquaculture. Bolder: Westeview Press, 1985. p.119-192.

Recebido em: 16/04/02

Aceito em: 16/09/02 